\title{
The Sample Entropy of Inter Spike-Intervals as a Possible Measure of Relations between Neuronal Activity and Individuum Behaviour ${ }^{+}$
}

\author{
Anastasiia Vladimirovna Bakhchina \\ Institute of Psychology of Russian Academy of Sciences, Saratov, Russia \\ + Presented at the Entropy 2021: The Scientific Tool of the 21st Century, 5-7 May 2021; Available online: \\ https://sciforum.net/conference/Entropy2021/.
}

Published: 5 May 2021

Relations between the non-linear structure of neuronal activity and the way that neurons are involved in the behaviour were studied. To describe the non-linear structure of neuronal activity, the complexity of inter-spike intervals sequences was assessed calculating the sample entropy (SampEn). The experimental data used in analyses consisted of recordings of singular neuronal activity in the cingulate cortex of rabbits performing cyclic appetitive operant behaviour. All neurons were divided into two groups: specialized cells $(\mathrm{N}=29)$ and cells with nonspecific activity $(\mathrm{N}=84)$. The specialization of a neuron in relation to a defined behaviour is assessed via the probability of activation in behavioral acts. Neuronal activity and behaviour were recorded during the first and the second week after rabbits reach the learning criterion (10 right behaviour cycles performance one after another).

SampEn of inter-spike intervals was significantly lower in the group of specialized cells than in the group of cells with nonspecific activity (Mann-Whitney test; $p=0.01$ ). Concurrently, the average frequency of spikes didn't differentiate between groups $(p=0.33)$. In the whole set of cells, SampEn didn't differ significantly between the first and the second weeks of training sessions $p=0.34$ ). Yet the group of specialized cells performed lower SampEn during the second week of training than the first week $(p=0.03)$. The group of cells with nonspecific activity showed higher SampEn during the second week of training than the first week $(p=0.02)$.

The results can reflect the difference in the constancy of relations between neurons in the group. Specialized cells have a more constant set and links between each other than cells that have unidentified specialization in the experiment. Their activity is less constant in the observed behaviour and they are more changeable in the set and the structure of links.

Supported by RSF Grant №18-78-10114.

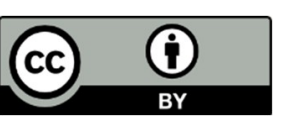

(C) 2021 by the author. Licensee MDPI, Basel, Switzerland. This article is an open access article distributed under the terms and conditions of the Creative Commons Attribution (CC BY) license (http://creativecommons.org/licenses/by/4.0/). 